\title{
Pulmonary injury after cardiopulmonary bypass: Beneficial effects of low-frequency mechanical ventilation
}

\author{
Hajime Imura, MD, ${ }^{\mathrm{a}}$ Massimo Caputo, MD, ${ }^{\mathrm{b}}$ Kelvin Lim, FRCS, ${ }^{\mathrm{b}}$ Masami Ochi, MD, ${ }^{\mathrm{a}}$ M-Saadeh Suleiman, DSc, \\ Kazuo Shimizu, MD, ${ }^{a}$ and Gianni D. Angelini, FRCS ${ }^{b}$
}

\begin{abstract}
Objective: Pulmonary dysfunction is a frequent postoperative complication after cardiac surgery with cardiopulmonary bypass, and atelectasis is thought to be one of the main causes. The aim of this study was to evaluate whether low-frequency ventilation and continuous positive airway pressure during cardiopulmonary bypass reduce postcardiopulmonary bypass lung injury.
\end{abstract}

\begin{abstract}
Methods: Eighteen Yorkshire pigs were subjected to 120 minutes of cardiopulmonary bypass (1 hour of cardioplegic arrest) followed by 90 minutes of recovery before being sacrificed. Six animals served as control with the endotracheal tube open to atmosphere during cardiopulmonary bypass. The remaining animals were divided into 2 groups of 6: One group received continuous positive airway pressure of $5 \mathrm{~cm} \mathrm{H}_{2} \mathrm{O}$, and one group received low-frequency ventilation (5/minutes) during cardiopulmonary bypass. Lung tissue biopsy and bronchoalveolar lavage samples were obtained before and 90 minutes after discontinuation of cardiopulmonary bypass for measurement of adenine nucleotide (adenosine-5' -triphosphate, adenosine diphosphate, adenosine monophosphate), lactate dehydrogenase, DNA levels, and histology. Hemodynamic data and arterial blood gases were also collected through the study.
\end{abstract}

Results: The hemodynamic parameters were similar in the 3 groups. After cardiopulmonary bypass, the low-frequency ventilation group showed significantly better oxygen tension and alveolar arterial oxygen gradient, higher adenine nucleotide, lower lactate dehydrogenase levels, and reduced histologic damage in lung biopsy, as well as lower DNA levels in bronchoalveolar lavage compared with the control group. The continuous positive airway pressure group showed only significantly reduced lactate dehydrogenase levels compared with control.

Conclusion: Low-frequency ventilation during cardiopulmonary bypass in a pig experimental model reduces tissue metabolic and histologic damage in the lungs and is associated with improved postoperative gas exchange.

Pulmonary injury after cardiopulmonary bypass (CPB) is a common complication in patients undergoing cardiac surgery and is associated with low arterial oxygen tension $\left(\mathrm{PaO}_{2}\right)$ or high carbon dioxide tension $\left(\mathrm{PCO}_{2}\right)$, which can continue for several days, leading to prolonged mechanical ventilation. $^{1-3}$ Inflammatory response to $\mathrm{CPB}^{4-6}$ and ischemic damage of the lungs ${ }^{7-10}$ have been considered as major causes of respiratory failure after cardiac surgery, and there have been numerous reports of successful reduction of postCPB lung injury by controlling inflammatory response ${ }^{4-6}$ or pulmonary ischemia. ${ }^{7-10}$ Nevertheless, few of these treatments or strategies have been applied in clinical practice.

The development of off-pump coronary artery bypass surgery has recently allowed researchers to investigate the

From the Department of Surgery, Division of Cardiovascular Surgery, Nippon Medical School, ${ }^{\mathrm{a}}$ Tokyo, Japan; and Bristol Heart Institute, Bristol University, ${ }^{\mathrm{b}}$ Bristol, United Kingdom.

Received for publication July 31, 2008; revisions received Oct 22, 2008; accepted for publication Nov 7, 2008.

Address for reprints: Hajime Imura, MD, Department of Cardiovascular Surgery, Nippon Medical School, 1-1-5 Sendagi Bunkyo-ku, Tokyo, 113-8603, Japan (E-mail: himura@nms.ac.jp).

J Thorac Cardiovasc Surg 2009;137:1530-7

$0022-5223 / \$ 36.00$

Copyright (c) 2009 by The American Association for Thoracic Surgery doi:10.1016/j.jtcvs.2008.11.014 effects of $\mathrm{CPB}$ in patients undergoing the same type of procedure. A significant lung injury has been reported even after off-pump coronary artery bypass grafting (CABG), ${ }^{11-13}$ which suggested that the inflammatory response and ischemia reperfusion to $\mathrm{CPB}$ may not be the only cause for pulmonary dysfunction.

Atelectasis is also regarded as a main cause of post-CPB lung injury, and a correlation between the degree of atelectasis and intrapulmonary shunt has been reported. ${ }^{14,15}$ It is known that ventilation or even keeping air in the alveoli protects the lungs from ischemic damage. Previous studies have shown that oxygen in the alveolar space helps keep tissue adenine nucleotides level and prevents histopathologic damage in the lungs during ischemia. ${ }^{16-19}$ In clinical practice, several studies have tried different ventilation strategies during $\mathrm{CPB}$, such as continuous positive airway pressure (CPAP) or high-frequency ventilation; however, none has provided evidence of significant beneficial effects on post-pump lung injury. ${ }^{20} \mathrm{~A}$ recent report has shown benefits of maintaining ventilation during $\mathrm{CPB}$ on post-CPB oxygenation and shorter mechanical ventilation, although its mechanism remained unclear. ${ }^{21}$

The aims of the present study were to investigate whether low-frequency ventilation (LFV) or CPAP during CPB reduces post-CPB lung injury and to address the underlying tissue metabolism and histopathologic mechanisms. 

Abbreviations and Acronyms
$\mathrm{A}-\mathrm{aDo}_{2}=$ alveolar arterial oxygen gradient
ADP $=$ adenosine diphosphate
AMP = adenosine monophosphate
ATP = adenosine- 5 -triphosphate
$\mathrm{BAL}=$ bronchoalveolar lavage
$\mathrm{CABG}=$ coronary artery bypass grafting
$\mathrm{CPAP}=$ continuous positive airway pressure
$\mathrm{CPB}=$ cardiopulmonary bypass
$\mathrm{LFV}=$ low-frequency ventilation
$\mathrm{PaCO}_{2}=$ arterial carbon dioxide tension
$\mathrm{PaO}_{2}=$ arterial oxygen tension
$\mathrm{PCO}_{2}=$ carbon dioxide tension
$\mathrm{PO}_{2}=$ oxygen tension

\section{MATERIALS AND METHODS \\ Animals}

Eighteen healthy Yorkshire pigs (body weight: $50-65 \mathrm{~kg}$ ) were purchased from a commercial breeder. All animals were treated in accordance with the Home Office Guidance on the Operation of Animals (Scientific Procedures) Act, 1986 (HMSO, London).

\section{Anesthesia and Surgery}

All animals were anesthetized with intramuscular injection of ketamine $(20 \mathrm{mg} / \mathrm{kg})$, which was followed by intravenous injection of thiopentone (20 $\mathrm{mg} / \mathrm{kg}$ ). Anesthesia was achieved by using diazepam ( $1 \mathrm{mg} / \mathrm{kg})$, fentanyl (15 $\mu \mathrm{g} / \mathrm{kg}$ for initial dose and $50 \mu \mathrm{g} / \mathrm{kg} / \mathrm{h}$ for maintenance), and propofol ( $1 \mathrm{mg} / \mathrm{kg}$ for initial dose and $6 \mathrm{mg} / \mathrm{kg} / \mathrm{h}$ for maintenance).

Animals were placed in a supine position and an endotracheal tube was inserted for mechanical ventilation, which started with $10 \mathrm{~mL} / \mathrm{kg}$ tidal volume, $15 / \mathrm{min}$ frequency, $100 \%$ of oxygen, and $0 \mathrm{~mm} \mathrm{Hg}$ of end-expiratory pressure. To obtain favorable arterial carbon dioxide tension $\left(\mathrm{PaCO}_{2}\right)(35.0$ $45.0 \mathrm{~mm} \mathrm{Hg}$ ) and $\mathrm{pH}(7.35-7.45)$, tidal volume was changed before surgery, whereas other settings were fixed. The right carotid artery and vein were exposed for monitoring arterial pressure and insertion of a Swan-Ganz catheter. The heart was then exposed via a median sternotomy, and CPB was established by cannulating the ascending aorta and right atrium. The flow, mean arterial pressure, and rectal temperature during $\mathrm{CPB}$ were maintained between 85 and $100 \mathrm{~mL} / \mathrm{kg}, 55$ and $65 \mathrm{~mm} \mathrm{Hg}$, and $37^{\circ} \mathrm{C}$, respectively. After 30 minutes of $\mathrm{CPB}$, the aorta was crossclamped for 1 hour, and myocardial protection was achieved by normothermic blood cardioplegia (St Thomas solution I: blood = 1:1, Martindale Pharmaceuticals, Romford, Essex, UK). Cardioplegia was administered for 2 minutes into the aortic root immediately after crossclamping the aorta and every 15 minutes thereafter. On removal of the aortic crossclamp, hearts were reperfused for 30 minutes before discontinuing CPB. During the CPB period, animals were randomly assigned by card allocation to 1 of the following 3 protocols $(n=6$ each): (1) Control: Ventilation was stopped, and the airway was opened to air; (2) CPAP: Airway pressure was kept at $5 \mathrm{~cm} \mathrm{H}_{2} \mathrm{O}\left(\mathrm{FIO}_{2}=0.21\right)$ without ventilation; or (3) LFV: Ventilation frequency was reduced to $5 / \mathrm{min}$ (fraction of inspired oxygen $=0.21$ ). Actual tidal volumes for the individual animals in the LFV group on CPB were $550 \mathrm{~mL}, 560 \mathrm{~mL}, 570 \mathrm{~mL}, 580 \mathrm{~mL}, 600 \mathrm{~mL}$, and $620 \mathrm{~mL}$. After the bronchoalveolar lavage (BAL) samples were collected, lung suction was routinely carried out before and at the end of $\mathrm{CPB}$. Lung re-recruitment maneuvers were also performed before the termination of $\mathrm{CPB}$. Mechanical ventilation was restarted under the same settings as pre-CPB just before weaning from CPB and until the result of the first blood gas analysis was available.

\section{Collection of Samples and Analysis}

Arterial blood gases and cardiac function were monitored throughout the protocol. Small-volume airway lavage $(0.5 \mathrm{~mL} / \mathrm{kg})$ fluid samples were collected before $\mathrm{CPB}$, immediately before stopping $\mathrm{CPB}$, on restarting mechanical ventilation, and 90 minutes after CPB ended. Lung biopsies were also collected at the same time points from the left lower lobe for metabolic and histopathologic examinations. The airway lavage procedure ${ }^{22}$ and measurements of protein and DNA in airway lavage were performed as previously described. ${ }^{23,24}$

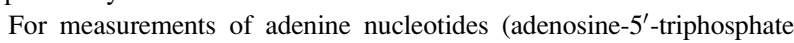
[ATP $]+$ adenosine diphosphate $[\mathrm{ADP}]+$ adenosine monophosphate [AMP]) and lactate level, tissue samples were immediately put into liquid nitrogen and stored at $-80^{\circ} \mathrm{C}$. Frozen tissue samples were crushed to powder in liquid nitrogen, transferred to ice cool $4.8 \%$ perchloric acid, and centrifuged at $4000 \mathrm{rpm}$ for 10 minutes at $4^{\circ} \mathrm{C}$. The supernatant was then neutralized using $0.44 \mathrm{~mol} / \mathrm{L} \mathrm{K}_{2} \mathrm{CO}_{3}$ and centrifuged again at $4000 \mathrm{rpm}$ for 10 minutes at $4^{\circ} \mathrm{C}$, after which the supernatant was collected for high performance liquid chromatography analysis. ${ }^{25}$ The concentrations of various adenine nucleotides (ATP, ADP, AMP) were measured using a high performance liquid chromatography machine according to Smolensky and colleagues. ${ }^{26}$ Lactate in the extract was measured using a kit from Sigma (Gillingham, Dorset, UK).

Histopathologic examination was performed by an experienced pathologist blinded to the randomization using a well-established method. ${ }^{27,28}$ In brief, for light microscopic examinations, the area of atelectasis or pulmonary edema was painted with a different color and an image of the colored photographs was taken with an image scanner (Hewlett Packard, Scanjet IICX/T, Palo Alto, Calif) using the adobe Photoshop program (Adobe Systems Inc, San Jose, Calif). The colored area was selected with Photoshop and measured with the Image 1.62 program (National Institutes of Health, Bethesda, Md). Ten representative photographs for each sample were analyzed. Pathologic findings were then graded on a scale of $(-)$ to $(+)$, which was determined on the basis of the percentage of the area of the specimen: $(-), 0 \% ;( \pm), 0 \%$ to $5 \% ;(+), 5 \%$ to $10 \% ;(++), 10 \%$ to $20 \%$. The results of electron microscopy are presented in a scale of $(-)$ to $(++)$ : $(-)$, absent or normal; $( \pm)$, present but not evident; $(+)$, present; $(++)$, abundantly present. Statistical analysis was then applied by converting the grading to ordinal numbers (grade $[-]=0,[ \pm]=1,[+]=2,[+H]=3$ ). The final grading results were determined from the median value of all observations in each respective group.

\section{Statistical Analyses}

All statistical analyses were performed using the Statistical Package for the Social Sciences 16.0J for Windows (SPSS Inc, Chicago, Ill). Because most of the data were not normally distributed, nonparametric tests were used for all analyses. Difference between groups was evaluated with Kruskal-Wallis test before Mann-Whitney $U$ test, and if the $P$ value was less than .05 , Bonferroni's correction was applied to the $P$ value of the Mann-Whitney $U$ test. To investigate the differences between pre-CPB values and measurements at different time points within each group, the Friedman test was performed initially, and if the $P$ value was less than .05 , the Wilcoxon test and Bonferroni's correction were applied to identify the significant differences.

\section{RESULTS}

\section{Hemodynamic Data}

Changes of hemodynamic parameters were similar in the 3 groups, although significant deteriorations were common after CPB. Pulmonary arterial pressure and cardiac output were deteriorated after CPB $(P<.05$ in Friedman test in each group); however, there were no significant differences in any parameters at each time point among the 3 groups (Figure 1). 

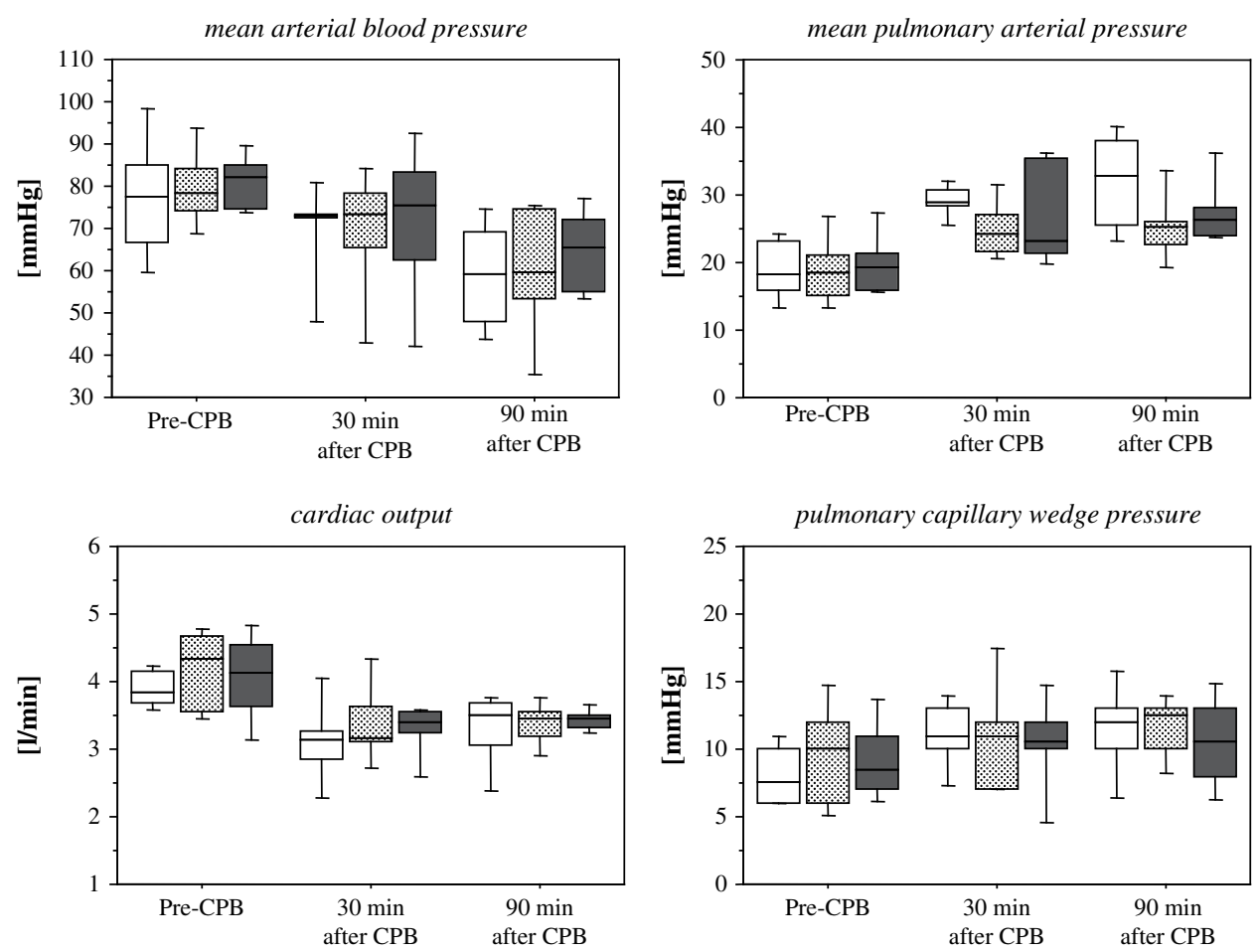

FIGURE 1. Changes in hemodynamic parameters. Control group (open boxes). LFV group (closed black boxes). CPAP group (small dots boxes). Boxes represent interquartile range (25th-75th percentile); line within each box represents median. Bars show 10th and 90th percentiles. $C P B$, Cardiopulmonary bypass.

\section{Changes in Arterial Blood Gas Analysis}

Changes in $\mathrm{PaO}_{2}, \mathrm{PaCO}_{2}$, and alveolar arterial oxygen gradient $\left(\mathrm{A}-\mathrm{aDo}_{2}\right)$ are shown in Figure 2. Only the LFV group showed no significant deterioration in $\mathrm{PaO}_{2}, \mathrm{PaCO}_{2}$, and $\mathrm{A}-\mathrm{aDo}_{2}$ during $\mathrm{CPB}$, and this was maintained throughout the post-CPB period. The CPAP group did not show significant deterioration in $\mathrm{PCO}_{2}$ immediately after $\mathrm{CPB}(P=.08)$, although the oxygen tension $\left(\mathrm{PO}_{2}\right)$ level was similar to control group. The LFV group showed significant improvements in $\mathrm{Po}_{2}$ and $\mathrm{A}-\mathrm{aDo}_{2}$ over the control group immediately after $\mathrm{CPB}$.

\section{DNA in Bronchoalveolar Lavage}

DNA level in BAL was increased during $\mathrm{CPB}$ in the control and CPAP groups $(P<.005$ and $<.01$, respectively, in Friedman test). Two hours after $\mathrm{CPB}$, mean values were still 2- to 4-fold higher but not statistically significant (Figure 3). The LFV group did not show a significant increase $(P>.1$ in Friedman test) after CPB and showed significantly less DNA level than in the control group but not in the CPAP group at the end of CPB.

\section{Tissue Adenine Nucleotides and Lactate}

Total adenine nucleotides (ATP + ADP + AMP) and ATP/ ADP ratio were decreased after $\mathrm{CPB}$ in the control group $(P=.01$ and .006 , respectively, in Friedman test), whereas no significant changes in these parameters were seen in the
LFV group. The CPAP group also showed a decrease in ATP/ADP ratio at the end of CPB $(P=.03$ in Friedman test, Figure 4). The LFV group showed higher adenine nucleotides level and ATP/ADP ratio after CPB over the control group. The CPAP group showed higher total adenine nucleotides level than control group, but this did not reach statistical significance.

Tissue lactate contents were increased during CPB in each group (control: $P=.009$, CPAP: $P=.006$ and LFV: $P=$ .018 in Friedman test, Figure 4). The increase was significantly less in the LFV group than in the control group. The CPAP group showed lower lactate level than the control group, although there was no statistical significance $(P<.1)$.

\section{Histopathologic Examinations}

Histopathologic changes examined through semiquantitative evaluation using light and electronic microscopic studies are presented in Table 1. Damage was summarized as atelectasia and pulmonary edema in light microscopy (Figure 5) and type I cell edema and microvilli diminutions of type II cell in electronic microscopy (Figure 6). Degrees of derangements were the worst in the control group (Figures $5, A$, and $6, A, B)$. The LFV group showed significantly less derangement than the control group during and after $\mathrm{CPB}$ in all pathologic examinations (Figures 5, $B, C$, and $6, C$; Table 1). The CPAP group showed improvements over the control group, although the benefits were less than in the LFV group (Figure 6, $D, E$; Table 1). 

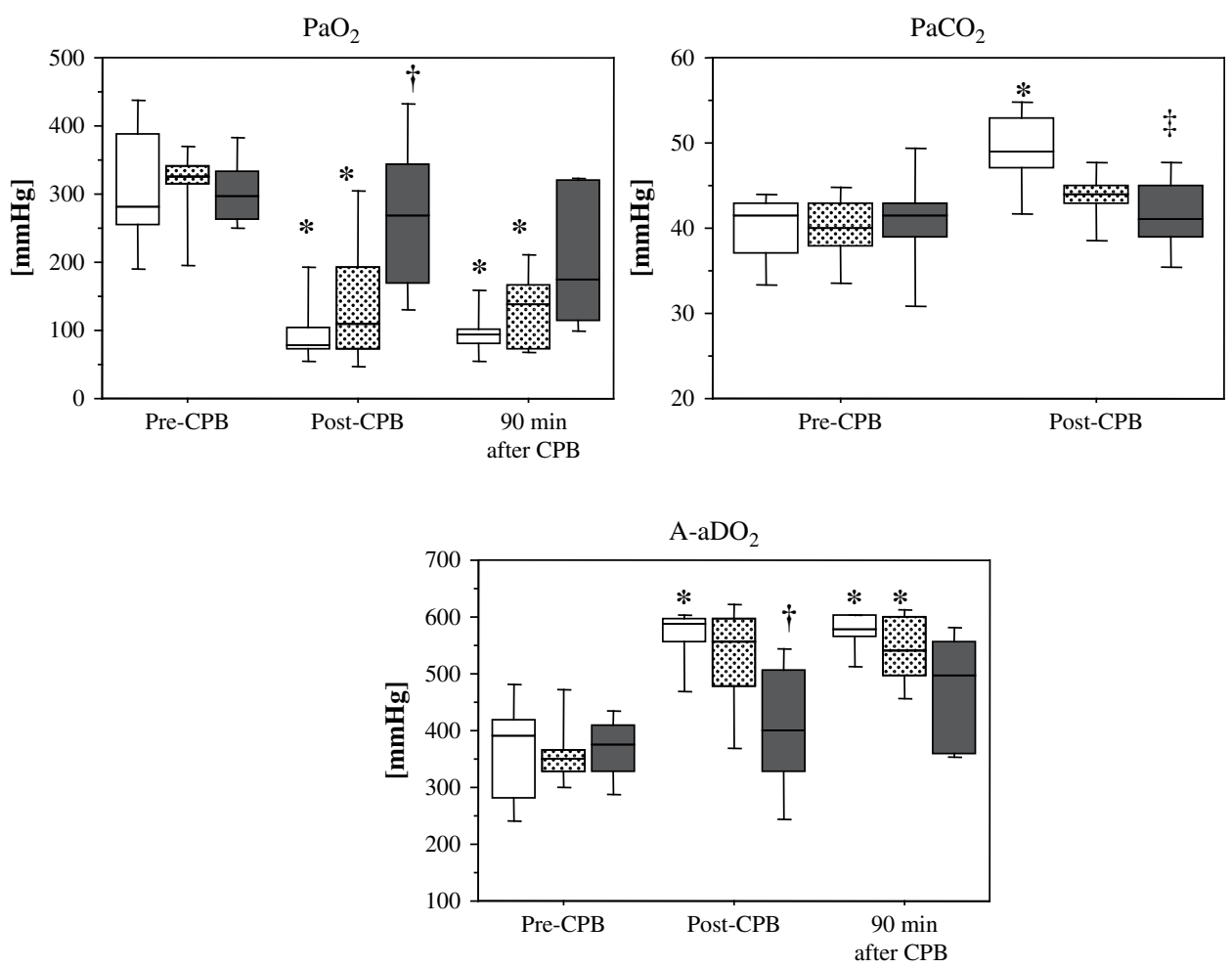

FIGURE 2. Changes in arterial blood gas analysis. Control group (open boxes). LFV group (closed black boxes). CPAP group (small dots boxes). Boxes represent interquartile range (25th-75th percentile); line within each box represents median. Bars show 10th and 90 th percentiles. $* P<.05$ in Friedman test and $P<.1$ vs pre-CPB value. $\dagger P<.05$ vs control group. $\ddagger P<.05$ in Kruskal-Wallis test and $P<.1$ vs control. $C P B$, Cardiopulmonary bypass; $\mathrm{PaO}_{2}$, arterial oxygen tension; $\mathrm{PaCO}_{2}$, arterial carbon dioxide tension; $\mathrm{A}-\mathrm{aDO}_{2}$, alveolar arterial oxygen gradient.

\section{DISCUSSION}

This study demonstrated metabolic and histologic damage in lung tissue in a pig model of CPB. These changes can be reduced by maintaining LFV for the duration of CPB. In our control group, the changes in tissue metabolites (ATP, ADP, AMP, and lactate) were similar to those seen in previous studies, ${ }^{16-19}$ although they were not statistically significant. Histopathologic examination also showed major atelectasis and pulmonary edema, although not severe enough to reach the level of acute respiratory distress syndrome. These findings confirm the validity of our experimental model and study protocols.

It is generally believed that one of the main causes of postCPB lung injury is the activation of the systemic inflammatory response. Previous experimental studies have tried to suppress this reaction by various pharmacologic, ventilation, or other strategies. Some have been tested in clinical practice; however, none has demonstrated better clinical outcomes despite some improved oxygenation of arterial blood in the early period after CPB ${ }^{29,30}$ Recent studies, in which the lung injury was compared between CABG with and without $\mathrm{CPB}$, showed no significant differences in postoperative arterial oxygen level and intubation period, suggesting that $\mathrm{CPB}$ is not the only cause of postsurgical lung injury. ${ }^{2,13}$

Lung atelectasis is one of the most common complications after major surgery. ${ }^{13,15}$ Evidence has been provided that the proportion of atelectasis area detected by computed tomography showed good correlation with intrapulmonary shunt ratio. ${ }^{15}$ It was also suggested that atelectasis seen after CPB is the result of opening the endotracheal tube to the atmosphere.

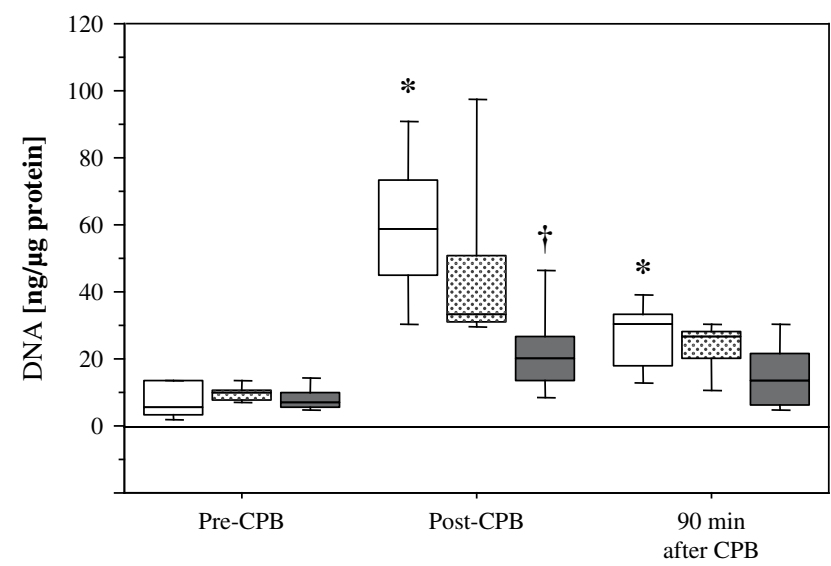

FIGURE 3. DNA level in BAL sample. Control group (open boxes). LFV group (closed black boxes). CPAP group (small dots boxes). Boxes represent interquartile range (25th-75th percentile); line within each box represents median. Bars show 10th and 90th percentiles. $* P<.05$ in Friedman test and $P<.1$ vs pre-CPB value. $\dagger P<.05$ vs control group. $C P B$, Cardiopulmonary bypass. 

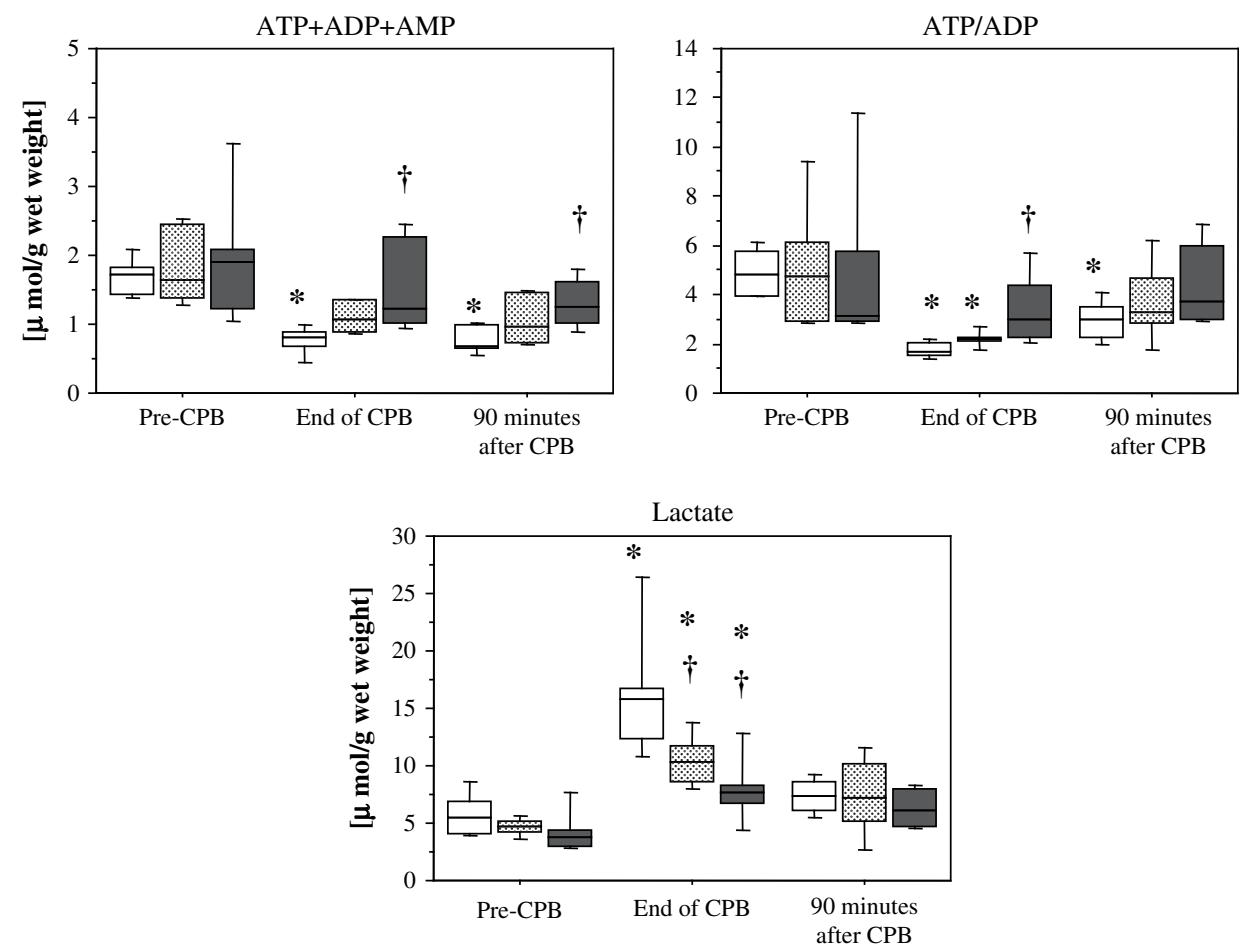

FIGURE 4. Changes in adenine nucleotides and lactate in lung tissue. Control group (open boxes). LFV group (closed black boxes). CPAP group (small dots boxes). Boxes represent interquartile range (25th-75th percentile); line within each box represents median. Bars show 10th and 90 th percentiles. $* P<.05$ in Friedman test and $P<.1$ versus pre-CPB value. $\dagger P<.05$ versus control group. $C P B$, Cardiopulmonary bypass; $A D P$, adenosine diphosphate; $A M P$, adenosine monophosphate; ATP, adenosine-5'-triphosphate.

Our findings supported the use of LFV (approximately half of pre-CPB frequency) to prevent atelectasis. A recent clinical study showed that ventilation during CPB in a patient undergoing $\mathrm{CABG}$ was associated with lower extravascular lung water and, more important, shorter postoperative extubation time. ${ }^{21}$ Other studies, however, have failed to demonstrate any benefit of ventilation during CPB on lung functions. ${ }^{20,31}$ The difference between the strategy in these studies and the strategy in this study was our choice to use LFV.

Several experimental models with CPB have also demonstrated the importance of keeping blood flow in the pulmonary artery. ${ }^{32,33}$ Gasparovic and colleagues ${ }^{34}$ reported that pulmonary lactate release after CPB was significantly higher in patients with prolonged mechanical ventilation and correlated to post-CPB $\mathrm{A}-\mathrm{aDo}_{2}$. In these reports, ischemia

TABLE 1. Semiquantification of histopathologic changes in lung tissues evaluated by light and electron microscopic examinations

\begin{tabular}{|c|c|c|c|c|}
\hline & Atelectasis & Pulmonary edema & Edema of type I cell & Disappearance of microvilli in type II cell \\
\hline \multicolumn{5}{|c|}{ (Before CPB) } \\
\hline LFV & $H$ & +1 & - & - \\
\hline CPAP & $H$ & - & - & - \\
\hline Control & $H$ & $+/$ & - & - \\
\hline \multicolumn{5}{|c|}{ (End of CPB) } \\
\hline LFV & $H+\dagger$ & $H+\dagger$ & $-\dagger$ & $-\dagger$ \\
\hline CPAP & $+*, \ddagger$ & $-\dagger$ & + & $-\dagger$ \\
\hline Control & $H^{*}$ & $t^{*}$ & $t^{*}$ & $+^{*}$ \\
\hline \multicolumn{5}{|c|}{ (90 min after $\mathrm{CPB}$ ) } \\
\hline LFV & $H-\dagger$ & $H+t$ & $-\dagger$ & $-\dagger$ \\
\hline CPAP & $+*$ & $+{ }^{*}$ & $-\ddagger$ & - \\
\hline Control & $H^{*}$ & $+^{*}$ & $+*$ & $+/$ \\
\hline
\end{tabular}



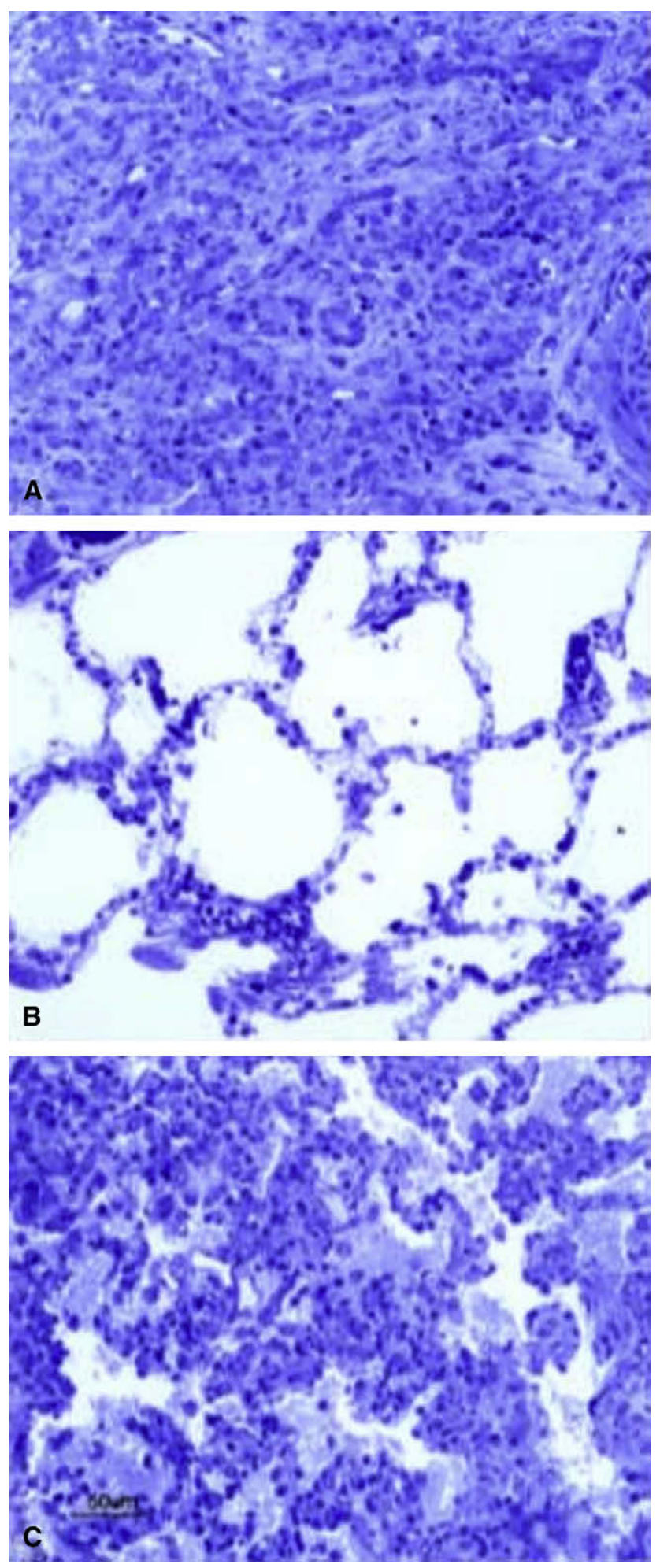

FIGURE 5. Light micrographs showing alveoli 90 minutes after CPB.

A, Control group showing many atelectasis and tissue pulmonary edema.

$\mathrm{B}$, LFV group showing normal lung tissue. C, CPAP group showing amorphous materials field in alveolar space. reperfusion was obviously one of the major causes of lung damage. We have previously demonstrated a relationship among CPB time, mucin increase, and lung injury after surgery with CPB. Arterial oxygen was strongly affected by mucin accumulation in alveolar space, and this correlates with CPB time. ${ }^{22}$ Furthermore, DNA level in BAL fluid suggested that pulmonary abnormalities after CPB was parallel to the degree of ischemic damage. There is evidence in the literature that ventilation or inflation of the lungs with oxygen or even air reduced ischemic damage in terms of metabolic and histologic changes in the lungs. ${ }^{16,19}$ Our study showed that LFV suppressed ischemic derangement in tissue metabolism and histopathologic changes in the lungs. The technique to decrease ischemic damage in our experimental model is based on ventilation and does not influence pulmonary flow. These findings may have important clinical implications because many cardiac surgeons believe that maintaining ventilation is more practicable than keeping blood flow to the lungs during cardiac operations.

There has been controversy whether CPAP during CPB can prevent post-CPB lung injury. ${ }^{35-38}$ Some reports have linked the use of CPAP $10 \mathrm{~cm} \mathrm{H}_{2} \mathrm{O}$ with higher arterial oxygen level and lower $\mathrm{A}-\mathrm{aDO}_{2}$ after $\mathrm{CPB}$. Concentration of oxygen during CPB is also controversial. Some recommended high concentration, ${ }^{38}$ but others suggested that this may exacerbate post-CPB lung injury. ${ }^{39}$ In our study, we adopted $5 \mathrm{~cm} \mathrm{H}_{2} \mathrm{O}$ as a pressure of CPAP because high pressure would interfere with the surgeon's work. The CPAP group showed trends toward "protection" in metabolites and blood gas, although it was not with statistical significance. The beneficial effect of CPAP may not have been fully realized because of our choice of low pressure.

LFV did not reduce visualization of the surgical field in our animal model. However, the technique may create some exposure and visualization problems during inflation of the lungs or increased blood flow return, particularly in mitral valve surgery.

\section{Study Limitations}

Lung edema was only assessed by histopathology, and lung pulmonary compliance was not recorded. Because of the short recovery protocol time, the beneficial effects of LFV may only be limited to the immediate period after discontinuation of CPB.

\section{CONCLUSIONS}

We demonstrated that LFV during CPB in an experimental pig model reduced tissue metabolic and histopathologic damages in the lungs and was associated with improved postoperative gas exchange. The mode of action of this technique is probably due to reduction in ischemic changes and prevention of atelectasis. The technique is safe and simple and can be readily applied in clinical practice. A prospective, randomized study will be necessary to determine whether 

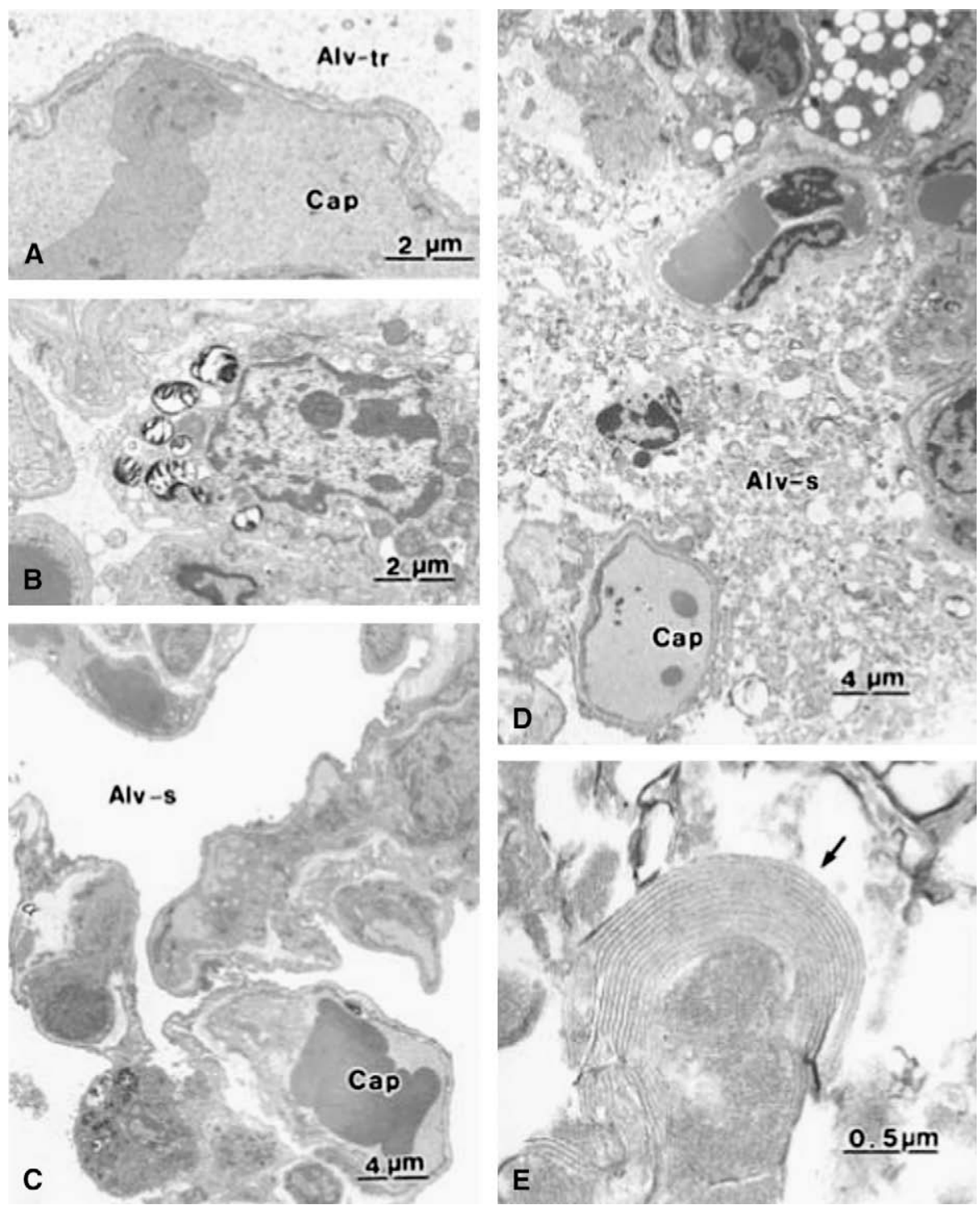

FIGURE 6. Electron micrographs showing alveoli 90 minutes after CPB. A, Cell edema is seen in type I alveolar epithelial cells (control group). B, Degenerated microvilli are seen in type II alveolar epithelial cells (control group). C, LFV showing no damages. D, Surfactant materials filed in alveolar space (CPAP group). E, Lamellar structures and onion-like surfactant materials structures (arrow) (CPAP group). Alv-s, Alveolar space; Alv-tr, alveolar transudate; Cap, capillary.

these experimental findings result in improved pulmonary function in clinical practice.

The study was supported by the British Heart Foundation. We acknowledge the excellent technical assistance of MRS. Hua Lin from the Bristol Heart Institute, and the great help of Dr. Shigeru Sato from the Nippon Medical School on histopathological examination.

\section{References}

1. Pinhu L, Whitehead T, Evans T, Griffiths M. Ventilator-associated lung injury. Lancet. 2003;361:332-40.

2. Zupancich E, Paparella D, Turani F, Munch C, Rossi A, Massaccesi S, et al. Mechanical ventilation affects inflammatory mediators in patients undergoing cardiopulmonary bypass for cardiac surgery: a randomized clinical trial. $J$ Thorac Cardiovasc Surg. 2005;130:378-83.
3. Marco RV, Peter S, Cosimo T, Renato DT, Jean Michael D, Antonio B, et al. Effects of mechanical ventilation on inflammatory mediators in patients with acute respiratory distress syndrome: a randomized controlled trial. JAMA. 2006;282:54-61.

4. Nakanishi K, Takeda S, Sakamoto A, Kitamura A. Effects of ulinastatin treatment on the cardiopulmonary bypass-induced hemodynamic stability and pulmonary dysfunction. Crit Care Med. 2006;34:1351-7.

5. Xiangming F, Yinglong L, Qiang W, Cuntao Y, Bo W, Yingmao R. Lung perfusion with Clarithromycin ameliorates lung function after cardiopulmonary bypass. Ann Thorac Surg. 2006;81:896-901.

6. Johnson D, Thomson D, Hurst TBM, Prasad K, Wilson T, Murphy F, et al. Neutrophil-mediated acute lung injury after extracorporeal perfusion. $J$ Thorac Cardiovasc Surg. 1994;107:1193-202.

7. Suzuki T, Ito T, Kashima I, Teruya K, Fukuda T. Continuous perfusion of pulmonary arteries during total cardiopulmonary bypass favorably affects levels of circulating adhesion molecules and lung function. J Thorac Cardiovasc Surg. 2001;122:242-8.

8. Schelensak C, Doenst T, Preußer S, Wunderlich M, Kleinschmidt M, Beyersdorf F. Cardiopulmonary bypass reduction of bronchial blood flow: a potential mechanism for lung injury in a neonatal pig model. $J$ Thorac Cardiovasc Surg. 2002;123:1199-205. 
9. Dodd-o JM, Welsh LE, Salazar JD, Walinsky PL, Peck EA, Shake JG, et al. Effect of bronchial artery blood flow on cardiopulmonary bypass-induced lung injury. Am J Physiol Heart Circ Physiol. 2004;286:H693-700.

10. Shoji T, Omasa M, Nakamura T, Yoshimura T, Yoshida H, Ikeyama K, et al. Mild hypothermia ameliorates lung ischemia reperfusion injury in an ex vivo rat lung model. Eur Surg Res. 2005;37:348-53.

11. Syed A, Fawzy H, Farag A, Nemlander A. Comparison of pulmonary gas exchange in OPCAB versus conventional CABG. Heart Lung Circ. 2004;13:168-72.

12. Heijmans JH, Liem KSAE, Damoiseaux GMC, Maessen JG, Roekaerts PMHJ. Pulmonary function and inflammatory markers in patients undergoing coronary revascularization with or without cardiopulmonary bypass. Anesthesia. 2007; 62:1233-40.

13. Groeneveld ABJ, Jansen EK, Verheij J. Mechanism of pulmonary dysfunction after on-pump and off-pump cardiac surgery: a prospective cohort study. $J$ Cardiothorac Surg. 2007;2:11-7.

14. Magnusson L, Zemgulis V, Wicky S, Tyden H, Thelin S, Hedenstierna G. Atelectasis is a major cause of hypoxemia and shunt after cardiopulmonary bypass. An experimental study. Anesthesiology. 1996;87:1153-63.

15. Verheiji J, van Lingen A, Raijmakers PG, Spijkstra JJ, Girbes AR, Jansen EK, et al. Pulmonary abnormalities after cardiac surgery are better explained by atelectasis than increased permeability oedema. Acta Anaesthesiol Scand. 2005;49: 1302-10.

16. Mordy DL, Chiu C-J, Hinchey EJ. The roles of ventilation and perfusion in lung metabolism. J Thorac Cardiovasc Surg. 1977;74:275-85.

17. Hamvas A, Park C-K, Palazzo R, Liptay M, Cooper J, Schuster DP. Modified pulmonary ischemia-reperfusion injury by altering ventilatory strategies during ischemia. J Appl Physiol. 1992;73:2112-9.

18. De Leyn PRJ, Lerut TE, Schreinemmakers HHJ, Van Raemdonck DEM, Mubagwa K, Flameng W. Effect of inflation on adenosine triphosphate catabolism and lactate production during normothermic lung ischemia. Ann Thorac Surg. 1993;55:1073-9.

19. Bishop MJ, Holman RG, Guidotti SM, Alberts MK, Chi EY. Pulmonary artery occlusion and lung collapse depletes rabbit lung adenosine triphosphate. Anesthesiology. 1994;80:611-7.

20. Zabeeda D, Gefen R, Medalion B, Khazin V, Shachner A, Ezri T. The effect of high-frequency ventilation of the lungs on postbypass oxygenation: a comparison with other ventilation methods applied during cardiopulmonary bypass. J Cardiothorac Vasc Anesth. 2003;17:40-4.

21. John LCH, Ervine IM. A study assessing the potential benefit of continued ventilation during cardiopulmonary bypass. Interact Cardiovasc Thorac Surg. 2008;7:14-7.

22. Imura H, Duncan P, Corfield P, Myerscough N, Caputo M, Angelini GD, et al. Increased airway mucin after cardiopulmonary bypass associated with postoperative respiratory complications in children. J Thorac Cardiovasc Surg. 2004;127: 963-9.

23. Bradford M. A rapid and sensitive method for the quantitation of microgram quantities of protein utilising the principle of protein-dye binding. Anal Biochem. 1976; 72:248-54.
24. Probert CS, Warren BF, Perry T, Mackay EH, Mayberry JF, Corfield AP. South Asian and European colitis show characteristic differences in colonic mucus glycoprotein type and turnover. Potential identification of a lower risk group for severe disease and cancer. Gut. 1995;36:696-702.

25. Imura H, Caputo M, Parry A, Pawade A, Angelini GD, Suleiman MS. Age-dependent and hypoxia-related differences in myocardial protection during pediatric open heart surgery. Circulation. 2001;103:1551-6.

26. Smolensky RT, Lachno DR, Ledingham SJM, Yacoub MH. Determination of sixteen nucleotides. Nucleotides and bases using high-performance liquid chromatography and its application to the study of purine metabolism in hearts for transplantation. J Chromatogr. 1996;527:414-20.

27. Sato $S$, Kishikawa T. Ultrastructural study of the alveolar lining and the bronchial mucus layer by block staining with oolong tea extract: the role of various surfactant materials. Med Electron Microsc. 2001;34:142-51.

28. Liu X-L, Sato S, Dai W, Yamanaka N. The protective effect of hepatocyte growthpromoting factor (pHGF) against hydrogen peroxide-induced acute lung injury in rats. Med Electron Microsc. 2001;34:92-102.

29. Ng CSH, Wan S, Yim APC, Arifi AA. Pulmonary dysfunction after cardiac surgery. Chest. 2002;121:1269-77.

30. Warren O, Alexiou C, Massey R, Leff D, Purkayastha S, Kinross J, et al. The effect of various leukocyte filtration strategies in cardiac surgery. Eur J Cardiothorac Surg. 2007;32:665-76.

31. Sasson L, Sherman A, Ezri T, Houri S, Ghilad E, Cohen I, et al. Mode of ventilation during cardiopulmonary bypass does not affect immediate postbypass oxygenation in pediatric cardiac patients. J Clin Anesth. 2007;19:429-33.

32. Richter JA, Meisner H, Tassani P, Barankay A, Dietrich W, Braun SL. Drew-Anderson technique attenuates systemic inflammatory response syndrome and improves respiratory function after coronary artery bypass grafting. Ann Thorac Surg. 1999;69:77-83.

33. Chai PJ, Williamson JA, Lodge AJ, Daggett CW, Scarborough JE, Meliones JN et al. Effects of ischemia on pulmonary dysfunction after cardiopulmonary bypass. Ann Thorac Surg. 1999;67:731-5.

34. Gasparovic H, Plestina S, Sutlic Z, Husedzinovic I, Coric V, Ivancan V, et al. Pulmonary lactate release following cardiopulmonary bypass. Eur J Cardiothorac Surg. 2007;32:882-7.

35. Berry CB, Butler PJ, Myles PS. Lung management during cardiopulmonary bypass: is continuous positive airway pressure beneficial? Br J Anaesth. 1993;71:864-8.

36. Magnusson L, Zemgulis V, Wicky S, Tyden H, Hedenstierna G. Effect of CPAP during cardiopulmonary bypass on postoperative lung function. Acta Anaesthesiol Scand. 1998;42:1133-8.

37. Loeckinger A, Kleinsasser A, Lindner KH, Margreiter J, Keller C, Hoermann C. Continuous positive airway pressure at $10 \mathrm{~cm} \mathrm{H} 2 \mathrm{O}$ during cardiopulmonary bypass improves postoperative gas exchange. Anesth Analg. 2000;91:522-7.

38. Hewson JR, Shaw M. Continuous airway pressure with oxygen minimizes the metabolic lesion of 'pump lung'. Can Anaesth Soc J. 1983;30:37-47.

39. Pizov R, Weiss YG, Oppenheim-Eden A, Glickman H, Goodman S, Koganov Y, et al. High oxygen concentration exacerbates cardiopulmonary bypass-induced lung injury. J Cardiothorac Vasc Anesth. 2000;14:519-23. 